\title{
Comparison of Different Pharmaceutical Preparations of Colchicine in Children with Familial Mediterranean Fever: Is Colchicine Opocalcium a Good Alternative?
}

\author{
Serkan Türkuçar ${ }^{1}$ (D), Gülçin Otar Yener ${ }^{2}$ (D), Hatice Adıüzzel Dundar ${ }^{1}$ (D), Ceyhun Acari ${ }^{3}$ (D), Balahan Makay $^{1}$ (D), \\ Selçuk Yüksel ${ }^{4}$ (D), Erbil Ünsal ${ }^{1}$ (1)
}

\begin{abstract}
${ }^{1}$ Department of Pediatric Rheumatology, Dokuz Eylül University School of Medicine, İzmir, Turkey
${ }^{2}$ Department of Pediatric Rheumatology, Şanlıurfa Training and Research Hospital, Şanlıurfa, Turkey

${ }^{3}$ Department of Pediatric Rheumatology, Malatya Training and Research Hospital, Malatya, Turkey

${ }^{4}$ Department of Pediatric Rheumatology, Pamukkale University School of Medicine, Denizli, Turkey
\end{abstract}

\begin{abstract}
Background: Colchicine is an anti-inflammatory agent used for preventing familial Mediterranean fever (FMF) attacks and amyloidosis. A significant number of patients are non-responsive or intolerant to the domestic drug colchicum dispert.

Aims: To compare the efficacy and side effects of colchicum dispert and colchicine opocalcium in children with FMF.

Study Design: Cross-sectional study.

Methods: A total of 29 children with FMF who used colchicum dispert for at least 6 months initially and colchicine opocalcium for another consecutive 6 months were included. Sex and gender equity in research was considered. Clinical features, visual analog scale for pain scores, exercise-induced leg pain, and FMF severity scores with laboratory parameters were evaluated for both the treatment periods. Bristol stool chart and number of stools per 24 hours were recorded to compare the gastrointestinal side effects.
\end{abstract}

Results: The major indication was non-responsiveness in 18 patients $(62 \%)$ and intolerance in 11 patients (38\%). Usage of colchicine opocalcium (significantly higher dosage than colchicum dispert) showed statistically significant beneficial effects on the number and duration of attacks, visual analog scale for pain, exercise-induced leg pain scores, and FMF severity scores $(\mathrm{p}<0.05$ for each parameter). Bristol stool chart questionnaire scores decreased from $5.62 \pm 1.56$ to $4.15 \pm 1.73$ points, and the scores of daily stool number decreased from $0.46 \pm 0.894$ to $0.03 \pm 0.118$ points $(\mathrm{p}<0.05)$. There were 12 patients who benefited from the switch without a change in dosage, and the clinical features were significantly better with the colchicine opocalcium treatment.

Conclusion: Pediatric patients with FMF, who have active disease and/ or gastrointestinal complaints during the use of colchicum dispert, may benefit from colchicine opocalcium.
Familial Mediterranean fever (FMF) is the most common autoinflammatory disease among Mediterranean populations that can cause serious complications, such as amyloidosis, without proper treatment (1). Colchicine is an herbal anti-inflammatory agent that is used for FMF treatment, obtained from the flower named Colchicine autumnale (2). After the first description of its efficacy in this disease by Ozkan and Goldfinger et al., it has been used as the cornerstone agent in FMF treatment $(3,4)$. It is shown that colchicine is very effective and safe in preventing FMF attacks and amyloidosis (5). On the other hand, there are remarkable number of patients who cannot tolerate the therapeutic doses of colchicine, owing to side effects, especially diarrhea. In addition, nearly $5 \%$ of patients are nonresponsive to colchicine treatment despite administering the maximum effective dose (6). Having M694V mutation and poor bioavailability owing to low intestinal absorption are the main reasons (7-9).

There are different pharmaceutical forms of colchicine in the market worldwide. Despite the contents of the same active ingredient in different doses, these preparations have different methods

Address for Correspondence: Serkan Türkuçar, Department of Pediatric Rheumatology, Dokuz Eylül University School of Medicine, İzmir, Turkey

e-mail: serkan_turkucar@hotmail.com

Received: May 27, 2020 Accepted: September 9, 2020 •DOI: 10.4274/balkanmedj.galenos.2020.2020.5.2205.220

Available at www.balkanmedicaljournal.org

ORCID iDs of the authors: S.T. 0000-0003-4700-1361; G.O.Y. 0000-0003-2575-6309; H.A.D. 0000-0003-1469-9900; C.A. 0000-0002-7175-0015; B.M. 0000-0001-6193-0402; S.Y. 0000-0001-9415-1640; E.Ü. 0000-0002-8800-0800. 
of production and excipients. In Turkey, pediatric rheumatologists initially use the domestic preparation available under the brand name $0.5 \mathrm{mg}$ Colchicum Dispert (CD) (Recordati, Turkey). This film-coated tablet form of colchicine preparation has $0.5 \mathrm{mg}$ of active ingredient and excipients, such as lactose, cornstarch, talc, Kollidon VA64, and magnesium stearate. They prefer to use Colchicine Opocalcium (CO) (Mayoly Spindler, France) that has $1 \mathrm{mg}$ of active ingredient, when the child is intolerant or nonresponsive to the domestic product. It is in the form of a compressed tablet, including several excipients, such as lactose, sucrose, povidone, magnesium stearate, and erythrosine aluminum lake.

This study aimed to compare the efficacy and side effects of CD and $\mathrm{CO}$ in pediatric patients with FMF. Is $\mathrm{CO}$ safer and more effective than $\mathrm{CD}$ ?

\section{MATERIALS AND METHODS}

\section{Patients}

The charts of 29 pediatric patients with FMF in 2 main pediatric rheumatology centers were reviewed retrospectively. Sex and Gender Equity in Research was considered (10). Patients were diagnosed as having FMF based on Ankara criteria (11). Demographic features such as age and gender with clinical features such as age at the time of the first attack, diagnosis, and MEFV mutations were noted. In addition, the indication of switching the 2 preparations were noted as "intolerance" or "nonresponsiveness." Nonresponders defined by using FMF-50 criteria, who did not show at least $50 \%$ improvement in 5 of the 6 criteria by 3 to 6 months or worsening at least 1 criterion (12). Informed consent forms were obtained from the parents of all patients.

\section{Clinical and laboratory assessment}

Patients who used CD at least 6 months initially and another 6 months of $\mathrm{CO}$ after switching from CD were included in the study. Patients were asked if they regularly used colchicine as prescribed and were defined as "compliant" if they took the recommended doses. The patients who missed drug doses were defined as "noncompliant." All the patients were compliant by their statements. $\mathrm{CO}$ was given to patients who were intolerant or unresponsive despite using $\mathrm{CD}$ at the maximum dose according to their weight and age. Drug doses, duration of treatments, number of attacks during the last 6 months, median duration of FMF attacks, visual analog scale (VAS) for pain scores, exercise-induced leg pain (EILP), and FMF severity score Pras et al. (13) were noted for both treatment periods separately. All of the clinical features during either attacks or attack-free periods (such as presence of fever, peritonitis, pleuritis, pericarditis, arthritis, and orchitis in attacks and erysipelas-like erythema, arthralgia, and myalgia in attack-free period) were recorded for both treatment periods. In addition, laboratory data indicating either inflammation or drug side effects (such as hemoglobin, white blood cell count, platelet count, neutrophil-to-lymphocyte ratio [NLR], mean platelet volume, alanine aminotransferase, erythrocyte sedimentation rate [ESR], and C-reactive protein [CRP], which were the most recent attack-free period values) were recorded.

\section{Questionnaire for gastrointestinal side effects}

Bristol stool scale was applied to all patients to investigate gas- trointestinal side effects for both treatment periods separately. The Bristol stool scale is a diagnostic tool designed to classify the form of human feces into 7 categories (14). Stool consistency decreases from types 1 to 7 . Type 6 stool is defined as mild diarrhea, and type 7 as severe diarrhea (Figure 1) (15). In addition, the number of stools per 24 hours was recorded using pediatric ulcerative colitis activity index (PUKAI), which is a useful tool for assessing the frequency of daily defecation and disease activity in patients with pediatric ulcerative colitis (16). The number of stools per day was scored between 0 and 3 (number of stools, $0-2=0$ point, $3-5=1$ point, $5-8=2$ points, $>8=3$ points) based on PUKAI.

Patients, who filled out the Bristol stool chart questionnaire as types 6 and 7, also answered the question about the number of stools per 24 hours because 2 or 3 points were included in the "intolerance group." Patients and their parents answered the questionnaire together.

\section{Uncommon side effects}

The less-frequent side effects of colchicine, such as nausea and vomiting, neuropathy, and myopathy for both drugs were noted based on medical history and records, separately.

\section{Statistical analysis}

Statistical analysis was performed using the Statistical Package for Social Sciences version 22 software (IBM SPSS Corp, Armonk, NY, USA). Shapiro-Wilk test was performed to evaluate the distributions of the values. Normally distributed values were presented as mean \pm standard deviation, and nonnormal values were presented as median and interquartile ranges (25\% to $75 \%)$. The numerical consecutive parameters of both treatment periods were evaluated with paired-sample $t$ test when normally distributed. If the distribution was nonnormally, the Wilcoxon paired rank test was performed. Clinical data of attacks were compared before and after switching preparation evaluated using the McNemar test. $\mathrm{p}<0.05$ was considered to be statistically significant.

\section{RESULTS}

\section{Demographic and clinical results}

There were 13 female (43.4\%) and 16 male patients (56.6\%), and the mean age was $14 \pm 3.8$ years. Nonresponsiveness to CD was the major indication for switching preparation in 18 patients $(62 \%)$, and intolerance was also noted in 11 patients (38\%) owing to gastrointestinal symptoms, that is, diarrhea. Notably, 19 patients had homozygous M694V mutation (62\%) and 27 patients had exon10 mutation in at least 1 allele of the MEFV gene (93\%). Only 2 patients had solely exon-2 mutations (one patient had E148Q/ R202Q and the other had R202Q variants). These patients were further observed for mutations on MVK, TNFRF1A, and NLRP3 genes and showed no mutations (Table 1), and were diagnosed as having FMF owing to typical clinical findings, as defined in the Ankara criteria.

\section{Clinical and laboratory results for both treatment periods}

The median duration for $\mathrm{CD}$ treatment was higher than that for $\mathrm{CO}$. The mean dose of CO was higher $(1.71 \pm 0.44 \mathrm{mg} /$ day $)$ than $\mathrm{CD}$ $(1.49 \pm 0.41 \mathrm{mg} /$ day $)$, and the difference was statistically significant $(\mathrm{p}<0.001)$. 


\begin{tabular}{|c|c|c|}
\hline Type 1 & Separate hard lumps & Severe constipation \\
\hline Type 2 & Lumpy and sausage like & Mild constipation \\
\hline Type 3 & A sausage shape with cracks in the surface & Normal \\
\hline Type 4 & Like a smooth, soft sausage or snake & Normal \\
\hline Type 5 & Soft blobs with clear cut-edges & Lacking fiber \\
\hline Type 6 & Mushy consistency with ragged edges & Mild diarrhea \\
\hline Type 7 & Liquid consistency with no solid pieces & Severe diarrhea \\
\hline
\end{tabular}

FIG. 1. Bristol Stool Chart.

TABLE 1. Demographic and clinical data of patients $(n=29)$

\begin{tabular}{|c|c|}
\hline \multirow[t]{2}{*}{ Gender } & 16 men $(56.6 \%)$ \\
\hline & 13 women $(43.4 \%)$ \\
\hline Age (year) & $14 \pm 3.8$ \\
\hline Age at first attack (year) & $6.7 \pm 4.11$ \\
\hline Age at the time of diagnosis (year) & $8.2 \pm 4.31$ \\
\hline Diagnosis lag time (year) & $1(0-9)$ \\
\hline \multirow[t]{2}{*}{ Indication for switch from $\mathrm{CD}$ to $\mathrm{CO}$} & Intolerance: $11(37.93 \%)$ \\
\hline & Nonresponsiveness: 18 (62.07\%) \\
\hline \multirow[t]{9}{*}{ Genetically assessment } & M694V (+/+): $n=9(\% 62)$ \\
\hline & M694V (+/-): $n=3(\%$ 10.3) \\
\hline & M694V/M680I/R202Q: n=1 (3.4\%) \\
\hline & M680I/V726A: n=1 (3.4\%) \\
\hline & M694V/R202Q: n=1 (3.4\%) \\
\hline & M680I/R202Q: n=1 (3.4\%) \\
\hline & V726A/E167D/F479L: $n=1(3.4 \%)$ \\
\hline & E148Q/R202Q: $n=1(3.4 \%) *$ \\
\hline & R202Q (+/-): $n=1(3.4 \%) *$ \\
\hline
\end{tabular}

*These patients were further searched for mutations on MVK, TNFRF1A, and NLRP3 genes and showed no mutations and they were diagnosed as having FMF owing to typical clinical findings as defined in the Ankara criteria
Regarding the comparative efficacy of the preparations, there was a substantial decrease in the number of attacks, from $4.83 \pm 2.1$ to $1.89 \pm 1.50$, at the end of 6 months of CO usage. In addition, the average duration of FMF attacks decreased from $63.98 \pm 25.84$ hours to $44.41 \pm 21.81$ hours, parallel with FMF severity scores (from $8.88 \pm 2.08$ points to $6.52 \pm 1.83$ ) during the same period. The musculoskeletal complaints also decreased from $7.36 \pm 1.43$ points to $2.84 \pm 1.77$ in terms of VAS scores of exercises induced leg pain. All mentioned clinical improvements were statistically significant $(\mathrm{p}<0.05)$

The use of CO was successful also in terms of controlling gastrointestinal symptoms. Bristol stool chart questionnaire scores decreased from $5.62 \pm 1.56$ to $4.15 \pm 1.73$ points, and scores of daily stool number decreased from $0.46 \pm 0.894$ points to $0.03 \pm 0.118$. The decrease in gastrointestinal complaints was statistically significant $(\mathrm{p}<0.05)$.

Laboratory markers of inflammation, such as NLR, ESR, and CRP values, decreased significantly on $\mathrm{CO}$ usage. In particular, NLR, the useful biomarker of subclinical inflammation, decreased from $2.43 \pm 1.72$ to $1.67 \pm 0.85$. Acute phase reactants (CRP and ESR) were in normal limits for both drugs, so comparison was insignificant (Table 2).

Results of patients treated with equivalent doses after switch There were 12 patients in whom colchicine dose remained the 
TABLE 2. Comparison of clinical and laboratory results for both preparations $(\mathrm{n}=29)$

\begin{tabular}{|c|c|c|c|}
\hline & $\begin{array}{l}\text { Colchicum } \\
\text { Dispert }\end{array}$ & $\begin{array}{l}\text { Colchicine } \\
\text { Opocalcium }\end{array}$ & $\mathrm{p}$ \\
\hline Duration of treatment (months) & $59.54 \pm 36.43$ & $26.39 \pm 16.64$ & $<0.001$ \\
\hline Dose (mg/day) & $1.49 \pm 0.41$ & $1.71 \pm 0.44$ & $<0.001$ \\
\hline $\begin{array}{l}\text { Number of attacks at the last } 6 \\
\text { months }\end{array}$ & $4.83 \pm 2.1$ & $1.89 \pm 1.50$ & $<0.001$ \\
\hline $\begin{array}{l}\text { Average duration of FMF attacks } \\
\text { (hours) }\end{array}$ & $63.98 \pm 25.84$ & $44.41 \pm 21.81$ & $<0.001$ \\
\hline EILP (attack-free period) & $7.36 \pm 1.43$ & $2.84 \pm 1.77$ & $<0.001$ \\
\hline FMF severity score & $8.88 \pm 2.08$ & $6.52 \pm 1.83$ & $<0.001$ \\
\hline Bristol stool scale & $5.62 \pm 1.56$ & $4.15 \pm 1.73$ & 0.044 \\
\hline Number of stools/24 h & $0.46 \pm 0.894$ & $0.03 \pm 0.118$ & $<0.001$ \\
\hline $\mathrm{Hb}(\mathrm{g} / \mathrm{dL})$ & $12.40 \pm 0.26$ & $12.75 \pm 0.76$ & 0.062 \\
\hline WBC $\left(/ \mathrm{mm}^{3}\right)$ & $7.654 \pm 2.290$ & $7.672 \pm 2.207$ & 0.958 \\
\hline Plt $\left(10^{3} / \mathrm{mm}^{3}\right)$ & $287 \pm 74$ & $293 \pm 46$ & 0.385 \\
\hline NLR (Neu/Lym) & $2.43 \pm 1.72$ & $1.67 \pm 0.85$ & 0.01 \\
\hline MPV (fL) & $7.99 \pm 1.56$ & $8.19 \pm 1.06$ & 0.224 \\
\hline $\operatorname{ALT}(\mathrm{U} / \mathrm{L})$ & $19.94 \pm 11.82$ & $24.61 \pm 12.83$ & $<0.001$ \\
\hline CRP (mg/L) & $\begin{array}{c}0.95 \\
(0.65-3.00) *\end{array}$ & $\begin{array}{c}0.66 \\
(0.03-2.10) *\end{array}$ & 0.044 \\
\hline $\operatorname{ESR}(\mathrm{mm} / \mathrm{h})$ & $27.07 \pm 13.03$ & $19.11 \pm 9.20$ & $<0.001$ \\
\hline \multicolumn{4}{|c|}{$\begin{array}{l}\text { *Mean } \pm \text { standard deviation } \\
* * \text { Median }\left(25^{\text {th }} \text { to } 75^{\text {th }} \text { percentile) }\right. \\
\text { ALT: Alanine Aminotransferase, CRP: C-Reactive Protein, EILP: Exercise-Induced Leg } \\
\text { Pain (Visual Analog Scale Score), ESR: Erythrocyte Sedimentation Rate, FMF: Famil- } \\
\text { ial Mediterranean Fever, Hb: Hemoglobin, MPV: Mean Platelet Volume, NLR: Neutro- } \\
\text { phil-to-Lymphocyte Ratio, Plt: Platelet Count, WBC: White Blood Cell Count. } \\
\text { Number of stool/24 hours: } 0-2: 0 \text { point, } 3-5: 1 \text { point, } 5-8: 2 \text { points, }>8: 3 \text { points }\end{array}$} \\
\hline
\end{tabular}

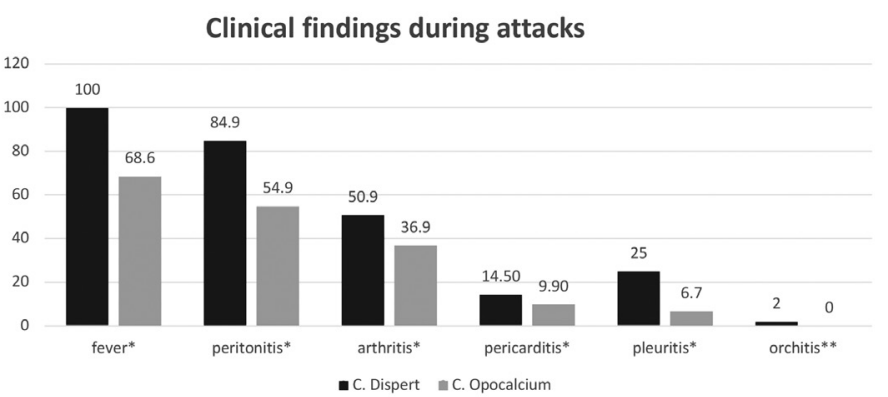

FIG. 2. Comparison of both colchicine treatment periods regarding clinical findings in FMF attacks.

*Statistically significant $(p<0.05) ;{ }^{* *}$ not statistically significant $(p>0.05)$

same. We further analyzed this group separately to see whether there was a bias in terms of change of dose. The results were similar to that of the whole group analysis. There was a significant decrease in the clinical findings, such as the number of attacks during the last 6 months, average duration of attacks, FMF severity score, and VAS scores of EILP $(p<0.05)$. In addition, the laboratory findings, such as NLR, ESR, and CRP values decreased after switching (Table 3).
TABLE 3. Clinical and laboratory data of the patients without dose change after preparation switch $(\mathrm{n}=12)$

\begin{tabular}{|c|c|c|c|}
\hline & Colchicum Dispert & $\begin{array}{l}\text { Colchicine } \\
\text { Opocalcium }\end{array}$ & $\mathrm{p}$ \\
\hline $\begin{array}{l}\text { Duration of treatment } \\
\text { (months) }\end{array}$ & $61.51 \pm 37.74 *$ & $19.76 \pm 15.34 *$ & $<0.001$ \\
\hline Dose (mg/day) & $1.71 \pm 0.45 *$ & $1.71 \pm 0.45^{*}$ & \\
\hline $\begin{array}{l}\text { Number of attacks at the } \\
\text { last } 6 \text { months }\end{array}$ & $5.22 \pm 2.09 *$ & $1.17 \pm 1.66^{*}$ & $<0.001$ \\
\hline $\begin{array}{l}\text { Average duration of FMF } \\
\text { attacks (hours) }\end{array}$ & $48(48-51)^{* *}$ & $24(24-30)^{* *}$ & $<0.001$ \\
\hline EILP (attack-free period) & $7.04 \pm 1.35^{*}$ & $2.29 \pm 1.90 *$ & $<0.001$ \\
\hline FMF severity score & $9.26 \pm 1.88 *$ & $5.92 \pm 2.08 *$ & $<0.001$ \\
\hline $\mathrm{Hb}(\mathrm{g} / \mathrm{dL})$ & $\begin{array}{c}12.26 \\
(12.27-12.33)^{* *}\end{array}$ & $\begin{array}{c}12.1 \\
(12.10-12.11)^{* *}\end{array}$ & 0.045 \\
\hline $\mathrm{WBC}\left(/ \mathrm{mm}^{3}\right)$ & $\begin{array}{c}6,560 \\
(6,560-6,590 * *)\end{array}$ & $\begin{array}{c}6,510 \\
(6,510-6,583)^{* *}\end{array}$ & 0.798 \\
\hline Plt $\left(10^{3} / \mathrm{mm}^{3}\right)$ & 249 (249-249.37) & $284(287.75)$ & 0.540 \\
\hline NLR (Neu/Lym) & $1.07(1.07-1.09)^{* *}$ & $1.07(1.04-1.07)^{* *}$ & $<0.001$ \\
\hline MPV (fL) & $8.10(8.10-8.11)^{* *}$ & $6.70(6.70-6.74)^{* *}$ & 0.046 \\
\hline $\operatorname{ALT}(\mathrm{U} / \mathrm{L})$ & $43(42-43)^{* *}$ & $45(41.37-45)^{* *}$ & $<0.001$ \\
\hline CRP (mg/L) & $1.54(1.54-1.64)^{* *}$ & $0.03(0.03-0.17)^{* *}$ & 0.01 \\
\hline $\operatorname{ESR}(\mathrm{mm} / \mathrm{h})$ & $44(41.75-44.00)^{* *}$ & $\begin{array}{c}23 \\
(21.25-23.00)^{* *}\end{array}$ & $<0.001$ \\
\hline
\end{tabular}

$*$ Mean \pm standard deviation; $* *$ Median $\left(25^{\text {th }}\right.$ to $75^{\text {th }}$ percentile $)$.

ALT: Alanine Aminotransferase, CRP: C-Reactive Protein, EILP: Exercise-Induced Leg Pain (Visual Analog Scale Score), ESR: Erythrocyte Sedimentation Rate, FMF: Familial Mediterranean Fever, Hb: Hemoglobin, MPV: Mean Platelet Volume, NLR: Neutrophil-to-Lymphocyte Ratio, Plt: Platelet Count, WBC: White Blood Cell Count.

\section{Results of clinical findings during attacks and attack-free periods}

Switching colchicine preparation influenced the presence of FMF symptoms during attacks, such as fever, peritonitis, pericarditis, pleuritis, arthritis, and orchitis. The existence of these clinical symptoms decreased significantly (Figure 2).

In addition, the presence of musculoskeletal complaints in attack-free period, such as arthralgia, myalgia, and erysipelas-like erythema decreased after switching. The improvement in arthralgia and myalgia complaints was statistically significant $(\mathrm{p}<0.05)$.

\section{DISCUSSION}

Colchicine is still the mainstay treatment option in FMF because its efficacy was determined in the 1970s $(3,4)$. However, today, approximately $5 \%$ of patients need biological treatment, particularly anti-interleukin-1 agents (anakinra, canakinumab), owing to intolerance or nonresponsiveness to colchicine $(5,17,18)$. On the other hand, the efficacy and side effects of different colchicine preparations can vary owing to their different production properties and distinct excipients. Therefore, switching colchicine preparations might be helpful in controlling the disease, before labeling the patient as "nonresponsive" or "intolerant" (19). In this study, we found that switching from CD to $\mathrm{CO}$ preparation had beneficial effects in diminishing gastrointestinal complaints and reducing disease activity. 
Clinical characteristics of disease such as FMF severity score, duration and frequency of attacks, and the severity of joint complaints in attack-free period benefited significantly after switching from $\mathrm{CD}$ to $\mathrm{CO}$. There is only one study in the literature evaluating the efficacy of a different pharmaceutical preparation of colchicine, in case of nonresponsiveness to one. Emmungil et al. (19) recently reported that there was a significant decrease in the severity and activity scores of the disease and the number of annual attacks after switching domestic colchicine preparations to CO. They attributed the effect of $\mathrm{CO}$ to its different pharmacokinetic properties. However, they did not evaluate "intolerance," which is in fact another major concern. Gastrointestinal side effects, especially diarrhea, are a very common restrictive cause for using the optimal dose of colchicine, especially in pediatric patients with FMF. In another recent study, Baglan et al. (20) reported that compressed film tablet (CO) was able to reduce the mean FMF attack duration and acute phase reactant levels during attack-free period, in their 35 pediatric patients with FMF. A meta-analysis by Stewart et al. (21) reported that the estimated relative risk of experiencing diarrheal symptoms in colchicine group was 2.44 (95\% confidence interval=1.69-3.62) compared with the control group. In our study, there were 11 patients $(38 \%)$ with gastrointestinal side effects who benefited from the switch. The frequency of diarrhea decreased, and this enabled us to increase the dose for the disease control. On the other hand, there were 12 patients who benefited from the switch without a change in dose. They had decreased FMF severity score, duration and frequency of attacks, and joint complaints as significant as the "dose increased" group. Our results showed that, despite no dose changes, the clinical features were better under $\mathrm{CO}$ treatment.

There are some limitations in this study. This is a retrospective study with a limited number of patients. A randomized controlled trial would yield more reliable results. In addition, there was a difference in the dose of $\mathrm{CO}$ after switching from $\mathrm{CD}$ between the centers. In fact, this difference cannot be considered as a bias, but an ability to increase the dose to control the disease activity.

The patients with FMF in the pediatric age group who have active disease and/or gastrointestinal complaints during the use of CD may benefit from CO. It might be a valuable treatment option before considering biological agents.

Ethics Committee Approval: Ethics committee approval was received for this study from the Ethical Committee of the Dokuz Eylül University, numbered as 2019/29-23 and dated 2 December 2019.

Patient Consent for Publication: Informed consent forms were obtained from the parents of all patients.

Author Contributions: Concept - S.T., E.Ü., B.M.; Design - S.T., B.M.; Supervision E.Ü., S.Y.; Resources - E.Ü., S.Y., G.O.Y.; Materials - H.D.A., C.A., G.O.Y., S.T.; Data Collection and/or Processing - S.T., G.O.Y.; Analysis and/or Interpretation - S.T., B.M., E.Ü.; Literature Search - B.M., S.T., S.Y., E.Ü.; Writing Manuscript - S.T., E.Ü.; Critical Review - E.Ü., S.Y., B.M.

Data-sharing Statement: N/A.

Conflict of Interest: The authors have no conflicts of interest to declare.

Funding: The authors declared that this study has received no financial support.

\section{REFERENCES}

1. Ozen S, Batu ED. The Myths We Believed in Familial Mediterranean Fever: What Have We Learned in the Past Years? Semin Immunopathol 2015;37:363-9. [Crossref]

2. Alkadi H, Khubeiz MJ, Jbeily R. Colchicine: A Review on Chemical Structure and Clinical Usage. Infect Disord Drug Targets 2018;18:105-21. [Crossref]

3. Ozkan E. A New Approach to the Treatment of Periodic Fever. Med Bull Istanbul 1972;5:44-9.

4. Goldfinger SE. Colchicine for Familial Mediterranean Fever. N Engl J Med 1972;287:1302. [Crossref]

5. Goldberg O, Levinsky Y, Peled O, Koren G, Harel L, Amarilyo G. Age dependent safety and efficacy of Colchicine Treatment for Familial Mediterranean Fever in Children. Semin Arthritis Rheum 2019;49:459-63. [Crossref]

6. Ozen S, Kone-Paut I, Gül A. Colchicine Resistance and Intolerance in Familia Mediterranean Fever: Definition, causes, and alternative treatments. Semin Arthritis Rheum. 2017;47:115-20. [Crossref]

7. Barut K, Sahin S, Adrovic A, Sinoplu AB, Yucel G, Pamuk G, et al. Familial Mediterranean Fever in Childhood: A Single-Center Experience. Rheumatol Int 2018;38:6774. [Crossref]

8. Lidar M, Yonath H, Shechter N, Sikron F, Sadetzki S, Langevitz P, et al. Incomplete Response to Colchicine in M694V Homozygote FMF Patients. Autoimmun Rev 2012;12:72-6. [Crossref]

9. Gül A. Approach to the Patients with Inadequate Response to colchicine in Familial Mediterranean Fever. Best Pract Res Clin Rheumatol 2016;30:296-303. [Crossref]

10. Heidari S, Babor TF, Castro P, Tort S, Curno M. Equidade de Sexo e Gênero na Pesquisa: Fundamentação Das Diretrizes SAGER e uso recomendado [Sex and Gender Equity in Research: Rationale for the SAGER Guidelines and Recommended Use]. Epidemiol Serv Saude 2017;26:665-75. [Crossref]

11. Yalçinkaya F, Ozen S, Ozçakar ZB, Aktay N, Cakar N, Düzova A, et al. A New Set of Criteria for the Diagnosis of Familial Mediterranean Fever in Childhood. Rheumatology (Oxford) 2009;48:395-8. [Crossref]

12. Ozen S, Demirkaya E, Duzova A, Erdogan O, Erken E, Gul A, et al. FMF Arthritis Vasculitis and Orphan Disease Research in Pediatric Rheumatology (FAVOR) and Turkish FMF Study Group. FMF50: A Score for Assessing Outcome in familial Mediterranean Fever. Ann Rheum Dis 2014;73:897-901.[Crossref]

13. Pras E, Livneh A, Balow JE Jr, Pras E, Kastner DL, Pras M, et al. Clinical Differences between North African and Iraqi Jews with Familial Mediterranean Fever. Am J Med Genet 1998;75:216-9. [Crossref]

14. Gulati R, Komuravelly A, Leb S, Mhanna MJ, Ghori A, Leon J, et al. Usefulness of Assessment of Stool Form by the Modified Bristol Stool Form Scale in Primary Care Pediatrics. Pediatr Gastroenterol Hepatol Nutr 2018;21:93-100. [Crossref]

15. Amarenco G. Bristol Stool Chart: Prospective and Monocentric Study of "Stools Introspection" in Healthy Subjects. Prog Urol 2014;24:708-13. [Crossref]

16. Kerur B, Litman HJ, Stern JB, Weber S, Lightdale JR, et al. Correlation of Endoscopic Disease Severity with Pediatric Ulcerative Colitis Activity Index Score in Children and Young Adults with Ulcerative colitis. World J Gastroenterol 2017;23:3322-9. [Crossref]

17. Eroglu FK, Beşbaş N, Topaloglu R, Ozen S. Treatment of Colchicine-Resistant Familial Mediterranean Fever in Children and Adolescents. Rheumatol Int 2015;35:1733-7. [Crossref]

18. Ozen S, Demirkaya E, Erer B, Livneh A, Ben-Chetrit E, Giancane G, et al. EULAR recommendations for the management of familial Mediterranean fever. Ann Rheum Dis 2016;75:644-51. [Crossref]

19. Emmungil H, İlgen U, Turan S, Yaman S, Küçükşahin O. Different Pharmaceutical Preparations of Colchicine for Familial Mediterranean Fever: Are They The same? Rheumatol Int 2020;40:129-35. [Crossref]

20. Baglan E, Ozdel S, Bulbul M. Do All Colchicine Preparations Have the Same Effectiveness in Patients with Familial Mediterranean Fever? Mod Rheumatol 2020;1-4. [Crossref]

21. Stewart S, Yang KCK, Atkins K, Dalbeth N, Robinson PC. Adverse Events During Oral Colchicine Use: A Systematic Review and Meta-Analysis of Randomised Controlled Trials. Arthritis Res Ther 2020;22:28. [Crossref] 